\title{
PENGUKURAN ORIENTASI PASAR PADA JENIS USAHA MIKRO, KECIL, DAN MENENGAH
}

\author{
Cecep Hidayat \\ School of Business and Management, BINUS University \\ Jln. K.H. Syahdan No. 9, Palmerah, Jakarta Barat 11480 \\ ceceph1267@yahoo.com
}

\begin{abstract}
The problem often faced in measuring market orientation of a business unit is to determine exact indicators of measurement. Small and medium-sized enterprises certainly have different characteristics that require appropriate indicators to measure market orientation. The objective in this study is to determine the dimensions and indicators for measuring market orientation in small and medium enterprise. To achieve the marketing objectives, marketing strategies are formulated that will adapt to internal and external environment. Strategic marketing is a marketing strategy based on market-driven. It means that the market needs is the basis of a marketing strategy. Research applied literature study with primary reference sources journal articles and books that discuss market orientation. Results of this literature study recommend that the dimension of the customer focus and competitor orientation is two dimensions that can be applied to measure market orientation for small and medium enterprises.
\end{abstract}

Keywords: strategic marketing, marketing strategy, market orientation, small and medium enterprises

\begin{abstract}
ABSTRAK
Permasalahan yang sering dihadapai dalam mengukur orientasi pasar sebuah unit usaha adalah menentukan dengan tepat indicator-indikator pengukuranya. Demikian juga sebuah usaha mikro, kecil, dan menengah tentunya memiliki karakteristik yang berbeda dengan unit usaha lain yang tentunya memerlukan indikator yang tepat untuk mengukur orientasi pasar. Tujuan penelitian ini dilakukan adalah untuk menentukan dimensi dan indikator untuk pengukuran orientasi pasar pada usaha mikro, kecil, dan menengah. Dalam rangka mencapai tujuan pemasaran, maka disusun strategi pemasaran yang akan dijalankan yang harus disesuaikan dengan lingkungan internal dan eksternal yang melingkupi. Pemasaran stratejik adalah suatu strategi pemasaran berdasarkan dorongan pasar, yang berarti bahwa kebutuhan pasar sebagai dasar dari penyusunan strategi pemasaran. Metode yang digunakan dalam penelitian ini adalah kajian literatur dengan sumber referensi utama berupa artikel jurnal, selain itu buku yang membahas tentang orientasi pasar. Hasil kajian literatur merekomendasikan bahwa dimensi fokus pada pelanggan dan orientasi pesaing adalah dua dimensi yang dapat diterapkan untuk pengukuran orientasi pasar jenis usaha mikro, kecil, dan menengah.
\end{abstract}

Kata kunci: pemasaran stratejik, strategi pemasaran, orientasi pasar, usaha mikro, kecil, dan menengah 


\section{PENDAHULUAN}

Memperoleh pasar pada dasarnya adalah hasil yang ingin dicapai oleh semua bentuk pemasaran. Pemasar melakukan kegiatan pemasaran bertujuan untuk memperoleh pasar dengan cara yang efisien dan efektif. Konsep pemasaran adalah sebuah konsep yang mengemukakan bahwa keinginan dan kebutuhan pasarlah yang menjadi titik awal semua aktivitas pemasaran. Dalam rangka mencapai tujuan pemasaran, maka disusun strategi pemasaran yang akan dijalankan yang harus disesuaikan dengan lingkungan internal dan eksternal yang melingkupinya.

Sebuah organisasi bisnis baik skala kecil, menengah, maupun besar pada umumnya menjalankan beberapa alternatif strategi yang disusun berdasarkan analisis lingkungan internal dan ekternal yang melingkupi dalam rangka mencapai tujuan utamanya yaitu tingkat profitabilitas yang maksimum. Tingkat keuntungan yang diperoleh oleh sebuah organisasi bisnis berkaitan erat dengan seberapa banyak ia memperoleh pangsa pasar dibandingkan para pesaing yang bergerak dalam usaha sejenis.

Untuk mencapai sasaran bisnis yaitu mendapatkan pangsa pasar sesuai dengan yang telah ditargetkan setiap unit memiliki beragam upaya dan cara yang bisa dilakukan. Cara-cara suatu bisnis melakukan upaya memperoleh pasar tersebut tersebut dikenal dengan istilah strategi pemasaran. Strategi pemasaran yang sudah tepat dan terbukti secara empirik efektif, dalam teori dikenal dengan istilah pemasaran stratejik. Pemasaran stratejik adalah suatu strategi pemasaran berdasarkan dorongan pasar, yang berarti bahwa kebutuhan pasarlah sebagai dasar dari penyusunan strategi pemasaran.

Usaha mikro, kecil, dan menengah (UMKM) tentunya memiliki karakteristik yang berbeda dengan usaha berskala besar. Dalam perekonomian Indonesia UMKM memiliki kontribusi yang sangat besar dalam menghasilkan pendapatan nasional. UKM adalah tulang punggung ekonomi Indonesia. Menurut menteri Koperasi dan Usaha Kecil Menengah, Syarif Hasan menyatakan dari puluhan juta UKM itu saat ini mewakili lebih dari 90 persen bisnis di Indonesia dan memberikan kontribusi sebesar 57 persen pada Produk Domestik Bruto (PDB) Indonesia (Sumetra, 2013).

Orientasi pasar merupakan konsep yang umum digunakan oleh semua organisasi bisnis. Berbagai teori, konsep, definisi, dan dimensi dari orientasi pasar banyak diungkapkan dalam berbagai literatur baik buku teks maupun jurnal ilmiah. Akan tetapi dalam praktiknya tidak semua teori dan konsep tersebut bisa diterapkan untuk setiap jenis dan ukuran unit usaha. Perlu penyesuaianpenyesuaian dalam aplikasi suatu metode pengukuran orientasi pasar. Konsep yang sudah dimodifikasi sesuai dengan karakeristik, kebutuhan, situasi, dan kondisi lingkungan mikro baik internal maupun eksternal ataupun kondisi lingkungan eksternal dinamakan konstruk. Pengukuran terhadap orientasi pasar suatu unit bisnis tentunya berdasarkan konstruk yang telah dibuat dengan indikator-indikator tertentu yang penyusunannya berdasarkan konstruk tersebut.

Usaha mikro, kecil, dan menengah memiliki karakteristik yang berbeda dengan unit usaha lainnya. Permasalahan yang sering terjadi adalah bagaimana menentukan dengan tepat indikatorindikator pengukuran orientasi pasar pada bentuk-bentuk usaha tersebut. Pengukuran orientasi pasar pada unit usaha ini tentunya memerlukan pertimbangan-pertimbangan tertentu yang disesuaikan dengan situasi dan kondisi lingkungan yang melingkupinya.

Penelitian literatur ini bertujuan untuk menentukan dimensi dan indikator yang tepat dapat digunakan untuk mengukur orientasi pasar pada usaha mikro, kecil, dan menengah. Adapun manfaat yang diharapkan dari hasil kajian literatur ini adalah dapat menghasilkan sebuah model konstruk yang dapat dijadikan pedoman dan bahan pertimbangan bagi para pemegang kepentingan dalam pengambilan keputusan yang berkaitan dengan pengukuran orientasi pasar sebuah usaha mikro, kecil, dan menengah. 


\section{METODE}

Metode yang digunakan dalam penelitian ini adalah kajian literatur (study literature) yang berupaya menganalisis konsep, definisi, dan dimensi konsep orientasi pasar (market-oriented) dari referensi-referensi yang dijadikan acuan dan bahan analisis. Adapun referensi utama yang dijadikan bahan analisis adalah berupa artikel-artikel utama yang terpilih dan buku teks yang berkaitan dengan konsep orientasi pasar serta peraturan perundangan yang berlaku berkaitan dengan usaha mikro dan kecil. Model pendekatan penulisan yang digunakan dalam tulisan ini adalah pendekatan dimensional (dimensional approach). Pendekatan dimensional melakukan kajian literatur dengan menganalisis dimensi-dimensi variabel market-oriented dari berbagai sudut pandang para ahli untuk selanjutnya dijadikan dasar bagi pengukuran orientasi pasar untuk jenis usaha mikro, kecil, dan menengah.

\section{HASIL DAN PEMBAHASAN}

Dalam rangka mendapatkan pasar, sebuah organisasi bisnis baik skala kecil, menengah, maupun besar pada umumnya menjalankan beberapa alternatif strategi yang disusun berdasarkan analisis lingkungan internal dan ekternal yang melingkupi sebuah organisasi. Sekumpulan alternatif strategi yang dapat dijalankan oleh sebuah organisasi pada umumnya tergambar dalam sebuah konsep yang dinamakan pemasaran stratejik. Pemasaran staratejik berkaitan dengan gambaran strategi-strategi apa yang perlu direncanakan dalam rangka mencapai tujuan dan sasaran organisasi. Stratejik atau strategis maksudnya adalah strateginya sudah terbukti tepat atau benar berdasarkan hasil penelitian dan kajian-kajian empirik di lapangan. Jadi dalam pemasaran stratejik dibahas alternatif-alternatif strategi pemasaran yang mungkin dapat diaplikasikan, dan tentunya disesuaikan dengan kondisi lingkungan internal dan eksternal organisasi. Salah satu definisi pemasaran stratejik adalah seperti yang dikemukakan oleh Cravens dan Piercy (2009:13): "Strategic marketing is market-driven process of strategy development, implementing, and managing the marketing program positioning strategies designed to meet the value requirements of the customers in each market target."

Berdasarkan definisi tersebut dapat dilihat bahwa pada dasarnya pemasaran stratejik adalah suatu strategi pemasaran berdasarkan dorongan pasar. Itu berarti bahwa kebutuhan pasar sebagai dasar dari penyusunan strategi pemasaran. Pada pembahasan market-driven strategy, Craven dan Piercy (2009) juga mencakup kajian tentang inovasi, dan bauran pemasaran. Berkaitan dengan pengertian pemasaran stratejik yang menekankan strategi berdasarkan dorongan pasar, maka pengukuran orientasi pasar menjadi suatu hal yang sangat penting untuk dijadikan bahan kajian baik secara teoritikmaupun empirik.

Pasar pada dasarnya adalah hasil dari kegiatan/proses yang bernama pemasaran, Pemasar melakukan kegiatan pemasaran adalah dalam rangka memperoleh pasar. Menurut Kotler dan Keller (2012) pasar berdasarkan pandangan para ahli ekonomi digambarkan sebagai kumpulan dari pembeli dan penjual yang melakukan transaksi suatu produk atau kelompok produk tertentu. Secara lebih spesifik pada bagian lain Kotler dan Keller mengatakan bahwa pemasar menggunakan istilah pasar untuk mencakup beragam kelompok konsumen. Adapun yang dimaksud beragam konsumen tersebut adalah pasar konsumen, perantara, manufaktur, dan sumber daya.

Menurut Best (2009) untuk mencapai orientasi pasar yang kuat, suatu bisnis perlu mengadopsi filosofi manajemen berdasarkan pasar (market-based management). Pada bagian lain ia mengemukakan bahwa manajemen berdasarkan pasar memerlukan suatu bisnis menggunakan ukuran kinerja pemasaran untuk mengukur profit pada tingkat pasar dan mencatat suatu keragaman indikator kinerja pasar lain yang berkaitan (Best, 2009). Berdasarkan pendapat tersebut pada dasarnya orientasi pasar menuntut suatu bisnis yang mendasarkan diri pada fokus terhadap pasar, dan pasar yang 
dimaksud adalah pelangan (customer). Fokus pada pelanggan akan kepuasan dan loyalltas dan pada akhirnya akan menumbuhkan profitabilitas bisnis.

Menurut Drumond, Ensor, dan Ashford (2009) terdapat 5 hal yang harus dilakukan untuk mencapai orientasi pasar, yaitu: (1) fokus pada pelanggan; (2) fokus pada pesaing; (3) memadukan pemasaran ke dalam bisnis; (4) visi stratejik; (5) ekspektasi yang realistis. Fokus pada pelanggan maksudnya adalah memahami konsumen dan responsif terhadap kebutuhannya. Rangkuman pengertian dari kelima elemen tersebut adalah fokus pada pesaing maksudnya adalah menjadi waspada dan menilai terhadap sasaran, strategi dan kapabilitas pesaing. Hal ini tentunya memerlukan studi banding dengan produk, proses, dan operasi pesaing. Memadukan pemasaran ke dalam bisnis maksudnya adalah bahwa pemasaran tidak sebatas pada departemen pemasaran saja, tetapi setiap fungsi dan orang dalam organisasi memiliki peranan dalam menciptakan nilai dan pencapain tujuan organisasi. Harapan yang realistis maksudnya adalah harapan yang disesuaikan dengan kapabilitas, sumber daya, dan kondisi eksternal.

Secara historis orientsi pasar menurut Drumond, Ensor, dan Ashford (2009) merupakan pengembangan dari tahapan konsep pemasaran sebelumnya, yaitu dimulai dari orientsi produksi, produk, penjualan, dan pasar. Berkaitan dengan tahapan perkembangan konsep pemasaran, Kotler dan Keller (2012) mengemukakan lima tahapan orientasi perusahaan terhadap ruang pasar, yaitu konsep produksi, produk, penjualan, pemasaran, dan pemasaran holistik (the holistic marketing concept). Pemasaran holistik merupakan konsep pengembangan dari konsep pemasaran, yang terdiri unsur pemasaran internal, terpadu, kinerja, kerelasian, dan kinerja. Konsep tersebut terutama sangat cocok diterapkan untuk perusahaan-perusahaan besar. Mengingat yang menjadi objek penelitian adalah usaha mikro, yaitu usaha perangkai bunga, maka orientasi pasar dalam konsep pemasaran seperti yang dikemukakan oleh Kotler dan Keller (2012) kurang tepat untuk diterapkan. Konsep Drumond, Ensor, dan Ashford (2009) masih relevan untuk diaplikasikan dalam penelitian ini sesuai dengan unit analisis.

Cravens dan Piercy (2009:4) mengemukakan beberapa pernyataan penting berkaitan dengan konsep orientasi pasar:

"Market orientation is a business perspectif that makes the customer the focal point of a company's total operations. "A business is market-oriented when its culture is system atically and entirely committed to the continuous creation of superior customer value." Importantly, achieving a market orientation involves the use of superior organizational skills in understanding and satisfying customer. Becoming market-oriented requires the involvement and support of the entire workforce. The organization must monitor rapidly changing customer needs and wants, determine the impact of these changes on consumer behavior, increase the rate of product innovation, and implement strategies that build the organization's competitive advantage."

Sejalan dengan pendapat yang dikemukan oleh Best (2009), pernyataan yang dikemukakan oleh Cravens dan Piercy (2009) memiliki titik perhatian serta tujuan yang sama. Perhatian dan tujuan mereka berfokus pada pelanggan dalam rangka mencapai tujuan utama organisasi yaitu profitabilitas. Profitabilitas yang dimaksud akan diperoleh oleh organisasi apabila pelanggannya terpuaskan. Berdasarkan pernyataan yang dikemukakan oleh Craven dan Piercy juga jelas terlihat bahwa orientasi pasar tersebut berkaitan erat dengan inovasi, yang bahwa inovasi tersebut menjadi variabel pembahasan yang akan dikaji dalam penelitian ini. Doyle (2004) menggambarkan tentang orientasi pasar sebagai berikut. 


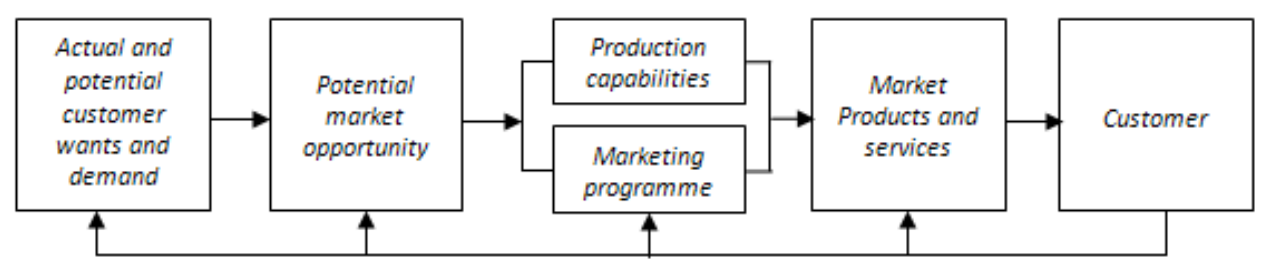

Gambar 1 Market Orientation

(Sumber: Doyle, 2004:75)

Perusahaan yang berorientasi pasar dimulai dengan mencari peluang pasar yang diciptakan oleh kebutuhan pelanggan yang belum terpenuhi. Kebutuhan ini diidentifikasi dengan mendengarkan dengan cermat permintaan pelanggan dan memantau perubahan teknologi dan lingkungan yang menimpa pada pasar. Dari serangkaian peluang yang bertujuan untuk memilih orang-orang yang terlihat paling potensial dan yang paling sesuai kompetensinya. Perusahaan lalu mengevaluasi kemampuan memproduksi dan program pemasaran yang perlu dilakukan dengan mengacu kepada sumber daya yang dimiliki. Service dan produk yang kemudian disesuaikan dengan masalah yang pelanggan miliki. Sepanjang proses, manajemen terus memperoleh umpan balik dengan mendengarkan pelanggan. Tujuannya adalah untuk menciptakan hubungan yang baik antara perusahaan dan pelanggan sedemikian rupa, sehingga kedua belah pihak melihat nilai dalam melakukan bisnis dengan satu sama lain selama jangka waktu tertentu (Doyle, 2004:75-76).

Menurut Johnson dan Wenstein (2004), karakteristik orientasi pasar dapat dibedakan secara jelas berdasarkan variabel-variebel pemasaran. Tabel 1 mengungkapkan perbedaan yang jelas antara konsep orientasi penjualan dengan orientasi pemasaran berdasarkan variabel-variabel pemasaran.

Tabel 1 Becoming Marketing-Oriented

\begin{tabular}{|c|c|c|}
\hline Marketing Variable & Sales Oriented & Market Oriented \\
\hline Starting point & Organization & Target Market \\
\hline Marketing focus & Product/Service & Customer Needs \\
\hline Customer focus & $\begin{array}{l}\text { New Business } \\
\text { (attraction) }\end{array}$ & $\begin{array}{l}\text { Existing customer base (growth and } \\
\text { retention) }\end{array}$ \\
\hline Competitive edge & Lowest delivered cost & Superior qulity or service \\
\hline Product strategy & Generic product & Augmented product \\
\hline Promotional strategy & Selling/adevertising & $\begin{array}{l}\text { Integrated marketing } \\
\text { communication }\end{array}$ \\
\hline Pricing strategy & Maxiizing/profit margin & Profitable use resources \\
\hline Marketing objective & Sales volume & Customer satisfaction \\
\hline Planning approach & Ractive & Proactive \\
\hline Time perspective & Short term (tactical) & Medium and long term (strategic) \\
\hline
\end{tabular}

Konsep orientasi pasar menurut Johnson dan Wenstein (2004) berbeda dengan konsep yang telah dikemukakan sebelumnya (Best, 2009; Drumond, Ensor, \& Ashford, 2009; Doyle, 2004). Mereka mengemukakan karakteristik konsep orientasi pasar secara lebih tegas dan jelas berdasarkan unsur-unsur dari variabel pemasaran. Dari seluruh variabel yang dikemukan dalam tabel, jika dikaitkan dengan usaha mikro dan kecil, hanya variabel promotional strategy yang kurang memungkinkan untuk diterapkan dalam perusahaan skala mikro dan kecil. 
Berkaitan dengan orientasi pasar, Walker dan Mullins (2011) mengemukakan beberapa karakteristik orientasi pasar. Karakteristik tersebut berdasarkan variabel yang berbeda dengan variabel yang dikemukakan Johnson dan Wenstein (2004), yaitu variabel aktivitas atau fungsi bisnis. Karakteristik orientasi pasar menurut Walker dan Mullins (2011) terlihat dalam Tabel 2.

Tabel 2 Perbedaan antara Production-Oriented dan Market-Oriented

\begin{tabular}{|c|c|c|}
\hline $\begin{array}{l}\text { Busines Activity } \\
\text { or Function }\end{array}$ & Sales Oriented & Market Oriented \\
\hline Product offering & $\begin{array}{l}\text { Company sells what it can make; } \\
\text { primary focus on functional } \\
\text { performance and cost }\end{array}$ & $\begin{array}{l}\text { Company makes what it can sell; primary } \\
\text { focus on customer needs and market } \\
\text { opportunities }\end{array}$ \\
\hline Product line & Narrow & Broad \\
\hline Pricing & $\begin{array}{l}\text { Based on production and distribution } \\
\text { cost }\end{array}$ & Based on perceived benefits provided \\
\hline Research & $\begin{array}{l}\text { Technical research; focus on product } \\
\text { improvement and cost cutting in the } \\
\text { production process }\end{array}$ & $\begin{array}{l}\text { Market research; focus on identifying new } \\
\text { opportunities and applying new technology } \\
\text { to satisfy customer needs }\end{array}$ \\
\hline Packaging & $\begin{array}{l}\text { Protection for the product; minimize } \\
\text { costs }\end{array}$ & $\begin{array}{l}\text { Designed for customer convenience; a } \\
\text { promotional tool }\end{array}$ \\
\hline Credit & $\begin{array}{l}\text { A Necessary evil; minimize bad debt } \\
\text { losses }\end{array}$ & $\begin{array}{l}\text { A customer service; a tool to attract } \\
\text { customers }\end{array}$ \\
\hline Promotion & $\begin{array}{l}\text { Emphasis on product features, } \\
\text { quality, and price }\end{array}$ & $\begin{array}{l}\text { Emphasis on product benefits and ability to } \\
\text { satisfy customer' needs or solve problems }\end{array}$ \\
\hline
\end{tabular}

(Sumber: Walker \& Mullins, 2011:15)

Penelitian orientasi pasar dengan objek perusahaan besar telah banyak dilakukan. Akan tetapi, untuk perusahaan kecil dan menengah masih relatif jarang. Salah satu peneliti yang meneliti orientasi pasar di perusahaan kecil dan menengah adalah Becherer, Haltead, dan Haynes (2001). Mereka mengemukakan bahwa berdasarkan hasil penelitian tentang hubungan karakteristik organisasi, tingkat kinerja bisnis, karaketeristik dan gaya pengambilan keputusan, dan pengalaman kewirausahna pemimpin akan menentukan keragaman orientasi pemasaran setiap UKM perusahaan kecil dan menengah terhadap orientasi pemasaran.

Menurut Lings dan Greenley (2005) pengukuran orientasi pasar lebih menekankan pada pengukuran internal organisasi. Adapun yang dimaksud dengan internal organisasi adalah kecenderungan pengukuran tersebut diarahkan pada sumber daya manusia yang ada dalam organisasi. Lings dan Greenley mengaitkan pengukuran orientasi pasar internal dengan pemasaran internal (internal marketing). Persamaan antara penelitian yang dilakukan oleh Becherer, Haltead, dan Haynes (2001) dan Lings dan Greenley (2005) adalah bahwa keduanya menekankan pada aspek lingkungan internal organisasi, yaitu sumber daya manusia.

Menurut Undang-undang No 8 tahun 2008 tentang usaha mikro, kecil dan menengah, kriteria usaha mikro adalah sebagai berikut: (a) memiliki kekayaan bersih paling banyak Rp50.000.000,00 (lima puluh juta rupiah) tidak termasuk tanah dan bangunan tempat usaha; atau (b) memiliki hasil penjualan tahunan paling banyak Rp300.000.000,00 (tiga ratus juta rupiah). Sedangkan kriteria usaha kecil adalah sebagai berikut: (a) memiliki kekayaan bersih lebih dari Rp50.000.000,00 (lima puluh juta rupiah) sampai dengan paling banyak Rp500.000.000,00 (lima ratus juta rupiah) tidak termasuk tanah dan bangunan tempat usaha; atau (b) memiliki hasil penjualan tahunan lebih dari Rp300.000.000,00 (tiga ratus juta rupiah) sampai dengan paling banyak Rp2.500.000.000,00 (dua milyar lima ratus juta rupiah). 
Pengukuran orientasi pasar (market orientation) pada usaha mikro dan kecil berdasarkan konsep-konsep yang telah dibahas yang dapat direkomendasikan adalah berdasarkan definisi dan dimensi dari Best (2009:523) namun dimensi yang digunakan harus disesuaikan sesuai dengan objek dan tujuan penelitian. Berkaitan dengan hal tersebut untuk usaha mikro dan kecil hanya dua dimensi yaitu fokus kepada pelanggan (customer focus), dan orientasi kepada pesaing (competitor orientation). Dimensi team approach tidak digunakan karena pada objek penelitian yaitu usaha mikro perangkai bunga tidak terdapat departemen. Jadi definisi orientasi pasar yang direkomendasikan untuk jenis usaha mikro dan kecil adalah sejauh mana usaha memiliki orientasi fokus pada pelanggan dan orientasi pesaing yang kuat untuk mengembangkan dan memberikan strategi berbasis pasar.

Dimensi dan indikator orientasi pasar yang dapat direkomendasikan untuk usaha mikro dan kecil adalah sebagai berikut. Pertama, fokus pada pelanggan yaitu tingkat dimana bisnis berusaha untuk memahami kebutuhan pelanggan dan menggunakan situasi, serta melacak kepuasan pelanggan. Indikatornya adalah selalu memahami kebutuhan pelanggan, selalu memahami keinginan pelanggan, selalu meminta tanggapan terhadap kepuasan pelanggan. Kedua, orientasi pesaing, yaitu tingat jejak bisnis strategi pesaing dan perbandingan kinerja relatif terhadap pesaing. Indikatotornya adalah selalu membandingkan strategi bisnis sendiri dengan pesaing, selalu membandingkan kinerja bisnis sendiri dengan pesaing, selalu mengantisipasi perubahan-perubahan strategi pesaing

\section{SIMPULAN}

Untuk mencapai orientasi pasar yang kuat, suatu bisnis baik perlu mengadopsi filosofi manajemen berdasarkan pasar. Demikian juga halnya usaha mikro dan kecil sebagai salah satu entitas bisnis yang turut menopang perekonomian Indonesia tidak lepas dari filosofi tersebut. Sejauh mana sebuah unit usaha berorientasi pasar memerlukan pengukuran yang tepat sesuai dengan karaketeristik jenis usaha tersebut serta situasi dan kondisi lingkungan internal dan eksternal yang melingkupinya.

Pengukuran orientasi pasar pada umumnya menekankan pada aspek sumber daya manusia sebagai pelaku dari pemasaran. Berdasarkan pembahasan teori dan konsep orientasi pasar yang telah dipaparkan dapat direkomendasikan bahwa dimensi yang dapat diterapkan untuk pengukuran orientasi pasar bagi usaha mikro dan kecil adalah fokus pada pelanggan dan orientasi pesaing. Indikator yang direkomendasikan untuk fokus pada pelanggan adalah selalu memahami kebutuhan pelanggan, selalu memahami keinginan pelanggan, selalu meminta tanggapan terhadap kepuasan pelanggan. Sementara indikator yang direkomendasikan untuk orientasi pesaing adalah selalu membandingkan strategi bisnis sendiri dengan pesaing, selalu membandingkan kinerja bisnis sendiri dengan pesaing, selalu mengantisipasi perubahan-perubahan strategi pesaing.

\section{DAFTAR PUSTAKA}

Becherer, R.C., Haltead, D., \& Haynes, P. (2001). Marketing orientation in SMEs: Effect of internal environment. Journal of Research in Marketing and Entrepreneurship, 3(1), 1-17.

Becherer, R.C., Haltead, D., \& Haynes, P. (2001). Marketing orientation in SMEs: Effect of internal environment. Journal of Research in Marketing and Entrepreneurship, 3(1), 1-17.

Best, R. J. (2009). Market-Based: Strategies for Growing Customer Value and Profitability (5th ed.). New Jersey: Pearson Education.

Cravens, D. W., \& Piercy, N. F. (2009). Strategic Marketing (9th ed.). New York: McGraw Hill. 
Doyle, P. (2004). Value-based Marketing: Marketing strategic for corporate growth and shareholder value. USA: John Wiley \& Sons.

Drumond, G., Ensor J., \& Ashford, R. (2009). Strategic Marketing: Planning and Control (3rd ed.). Elsevier.

Johnson, W. C., \& Weinstein A. (2004). Superior Customer Value in the New Economy: Concept and cases. CRC.

Kotler, P., \& Keller K. L. (2012). Marketing Management (14th ed.). Pearson.

Lings, I., \& Greenley, G. (2005). Measuring internal market orientation. Journal of Service Research, 7(3), 290-305.

Sumetra, D. P. (2013). Perkembangan Usaha Kecil Menengah (UKM) di Indonesia kian meningkat dan kini mencapai 55,2 juta yang tersebar di seluruh Indonesia. Diakses 20 Agustus 2014 dari http://nasional.inilah.com/read/detail/2026676/jumlah-ukm-di-indonesia-capai-552juta\#.U_9INqOTOjw

Undang-undang No 8 tahun 2008 tentang Usaha Mikro, Kecil, dan Menengah.

Walker, O. C., \& Mullins, J. W. (2011). Marketing Strategy (7th ed.). McGraw Hill. 